\title{
Accounting as Myth Maker
}

\author{
Kathy Rudkin, \\ School of Accounting \& Finance, University of Wollongong.
}

\begin{abstract}
Accounting is not only a technical apparatus, but also manifests a societal dimension. This paper proposes that accounting is a protean and complex form of myth making, and as such forms a cohesive tenet in societies. It is argued that there are intrinsic parallels between the theoretical attributes of myth and accounting practice, and that these mythical characteristics sustain the existence and acceptance of accounting and its consequences in societies over time. A theoretical exploration of accounting as a form of myth reveals accounting as pluralistic and culturally sensitive. Such an analysis challenges theoretical explanations of accounting that are presented as a "grand narrative" universal understanding of accounting. Manifestations of the attributes of myth are described in the calculus and artefacts of accounting practice to demonstrate how accounting stories and beliefs are used as a form of myth by individuals to inform and construe their world picture.
\end{abstract}

Key Words: myth; accounting; society.

\section{INTRODUCTION}

This paper argues that the practice of accounting is a complex form of myth-making. Accounting is more dynamic and sophisticated than merely being a commercial technology. It also fulfils a myth role in society. The development of the practice of accounting as part of the Enlightenment ${ }^{1}$ movement is well documented (Kedslie 1990, Mathews et al. 1996, Gaffikin 1988). Consequently the accounting discipline has emerged as a technology embracing a dominating positivistic approach. While texts of critical accounting challenge this positivistic understanding of accounting (Tinker et al 1982, Chua 1986[a], Chua 1986[b], Francis 1990, Dillard 1991) few have considered the mythical role that accounting may play in society (Pondy 1983, Gambling 1985). This paper explores how accounting has also inculcated mythical stories and beliefs to wider society, which individuals use innately to construe their world picture. This paper argues accounting is more than an unequivocal technical communication, and that it is rhetorical (Young 2003), where inter-subjective meanings are given to and believed by members of society (Dillard 1991). Understanding the use of accounting as a myth making device is important because it further challenges and obfuscates current one dimensional scientific, technological and functional approaches embedded in positive accounting discourses based on

\footnotetext{
${ }^{1}$ The Enlightenment is an intellectual movement originating in Europe in the late $17^{\text {th }}$ and $18^{\text {th }}$ centuries. It embraced the notion of scientific thought and reason as the only valid source of human knowledge, as opposed to superstition. It advocated for religious tolerance and is exemplified by the work of Bacon, Newton, Locke and Descartes.
} 
economic and behavioural science theories (Watts 1995, pp297-298). It offers a richer, more context bound and textural approach to understanding how accounting engages with the world.

Myth is intrinsic to past and present cultures and societies, but there is no direct or unanimous definition of myth. A layperson's understanding of myth is that it is something untrue. Myth comes from the Greek work mythos, and in this early form represented an oral culture of story telling. Barthes (1957) takes this linguistic approach and regards myth as a type of speech with historical origins. This is in contrast to the opposing notion of logos which tells the absolute truth (Burn 1970). Over time the meaning of myth has changed and various labels and terminologies have emerged to encompass myth styles. Sagas are myths that have a basis in history such as the story of the Trojan horse. Legends originally came from stories about saints (the Latin legenda) and are believed to have some truth to them. Folktales emerged in the nineteenth century where traditional stories were used for moralising as well as entertainment, with recurring motifs, while fairy stories were a more derogatory form of folk tale because of a tone of disbelief (Dowden 1992). However, they all rely on a willing suspension of disbelief to differing degrees by their audience, and are valued as communicating in an intangible way knowledge or values to a society.

The Enlightenment period saw the discrediting of myth as a form of valid knowledge, and the consequential historical rift between the credibility and explanations and descriptions of a scientific nature, as opposed to a mythical nature. Yet despite this, secular traces of myth in current societies can be found, such as the New Zealand rugby players who perform the Haka of Ka Mate. Santa Claus, Father Christmas and St. Nicholas are also dominant in many cultures as a mythical benevolent archetype. While these characters are not believed as real (except by the very young), they are believed as having some worth and represent wider societal values and ideals that are real. Frye (1982, p47) states "There are and remain two aspects of myth: one is its story-structure, which attaches it to literature, the other is its social function as concerned knowledge, what it is important for a society to know". The Australian Oxford Dictionary (1989) defines myth as "an idea that forms part of the beliefs of a group or class but is not founded on fact".

Rather than attempting to define myth, other approaches to understanding myth have been documented, as demonstrated by Kolakowski (1972) who writes

I attempt to employ the generalized concept of myth as a net to catch a permanently constitutive element of culture, and thus to create a somewhat different principle of classifying phenomena than is most often accepted in the philosophy of culture. I am convinced that the crucial boundary between the mythological layer of culture and its technological and scientific layer runs differently from what might be judged on the basis of most generally known functional interpretations of man's mythological creativity...I am, therefore, attempting to trace the presence of myth in non-mythical areas of experience and thought.

(Kolakowski 1972, pp.X-xi) 
As a contribution to this literature, such an approach is taken in this paper. The presence of myth will be traced in accounting, an area not traditionally associated with mythical experience and thought. This paper will look for attributes of accounting that rely upon a willing suspension of disbelief by the user, and identify underlying motifs that accounting practitioners communicate as important for society to know. This analysis offers a deeper and more pluralistic and culturally sensitive cognizance of accounting practice. Such an approach is offered in response to calls for alternative accounting research (Hopwood 1978, Burchell et al. 1980, Tinker et al. 1982, Cooper and Hopper 1987). Myth theory offers a new paradigm to understand accounting because it embraces the values of the culture in which it is practiced. It demonstrates accounting to be an oracle foretelling social and cultural beliefs at the deshi ${ }^{2}$ level, from multiple perspectives of identifying group affiliations (Agger 1991, pp112-116). The application of theoretical understandings of myth allow understandings of accounting to go beyond "grand narratives" as explanations for the social, cultural and historical understandings of accounting, rejecting a positivist "grand narrative" in favour of the privileging of small and heterogeneous narratives of individuals and groups in specific social contexts, as proposed by Lyotard (1984). This escapes applying a theory derived in the tradition of the global perspective view of the Enlightenment, a period where myth knowledge dramatically departed from scientific positivistic knowledge.

The following section two of this paper describes the stages of myth development, namely archaic myth, derivative myth and ideological myth, and gives examples of them present in the practice of accounting. Section three expands a discussion of ideological myth, specifically describing the nine attributes of ideological myth and explores their relevance to understanding accounting beyond technical aspects. The fourth section describes three common myth themes that are identified in accounting. The fifth section offers a conclusion as to the relevance and contribution of the analysis.

\section{FOUR STAGES OF MYTH DEVELOPMENT.}

A myth can operate at varying degrees of sophistication simultaneously, affecting different groups. In this way a myth can manifest itself in a very simple form to one group, and a more complex form to another group. Day (1984, pp3-16) identifies four stages of myth development. They exist along a continuum, and elements of a more elementary stage exist at any one time with elements of a more sophisticated stage. These stages of myth development are termed archaic myth, intermediate myth, derivative myth and ideological myth.

Archaic myth is largely non-literate and as such is communicated in story form, and its facts are believed to be genuinely true by its participants. The thirty second sound bite financial reporting at the end of a news bulletin after the close of the market, or promotional publicity of a company that accompanies a share float which is accepted in an unquestioned manner are contemporary examples of this.

\footnotetext{
${ }^{2}$ Deshi in this sense refers to the practice and understanding of accounting at the site specific level, or immediate local level. It is the cultural interpretation of the meaning of the accounts in an organization. This may be seen as a derogatory or unsophisticated understanding of the accounts.
} 
Intermediate myth, while still holding its abstractions to be absolutely true, communicates these truths in a written story form. An analogy would be individuals who have no or poor financial literacy accepting as unequivocal the profit figure on a financial statement, without realizing the possibilities or choices such as depreciation methods in the accounting standards that also make valid other representations. Derivative myth, next along the continuum, is much more a creature of the secular world. While not depending on absolute belief, it requires a suspension of disbelief, and uses devices such as superheroes and heroic quests to teach fundamental truths. The pervasive belief in the power of the market (the hero) to deliver economically rational decisions (the heroic quest) can be aligned with derivative myth, as daily market failures in the form of corporate collapses such as Enron, HIH and similar are regarded as aberrations and result in a suspension of disbelief in the fallibility of financial market structure (Sterling 1990, Chwastiak 1999). To admit the possibility of capital markets not working is to admit to a chaotic irrational form.

\section{IDEOLOGICAL MYTH}

The most sophisticated stage of development is that of ideological myth, which is embodied in texts. Such texts for accounting are financial statements and accounting records. Ideological myth is believed to hold valuable knowledge and guidance, the relevance of which is timeless. Ideological myth has nine identifying attributes (Day 1984): first myth is protean; secondly myth gives meaning, order and stability; thirdly myth is widely believed with profound intensity; fourthly scientifically myth cannot be proven or not proven; fifthly myth is held to be sacred but not necessarily religious; sixthly myth takes a narrative form; seventhly myth settings are outside chronological time; eighthly myth contains symbolism; and ninthly myth is held to provide valuable knowledge and guidance.

It is proposed that accounting is protean in nature. Levi-Strauss $(1978, \mathrm{p} 19)$ notes that cultures have not systematically or methodically differentiated themselves from each other. One way in which cultures are differentiated is in the form of their myths. If accounting is understood as an artefact which is socially constructed and socially constructing (Burchell et al. 1980, Tinker et al. 1982, Chua 1986(a), Chua 1986(b), Laughlin 1987, Lehman and Tinker 1987, Gaffikin 1988, Hines 1988, Morgan 1998, Arrington and Francis 1989), in this context it can be argued that accounting is a technology capable of generating and sustaining myths in organizations and societies. The protean nature of accounting can be seen in how it has differentiated itself and manifested different forms in response to the culture and chronology in which it operates, but its basic necessity to society remained throughout. Gambling (1985) argues that the physical attributes of business are not static and develop and change over time. Indeed, even in any one society the application of accounting is pluralistic and manifests itself in many forms, from small businesses using cash accounting or a simple double entry accounting system to large firms dealing with multidimensional and disaggregated accounting systems (Dunn and McCarthy 1997). Just as accounting can be shown to display protean attributes with respect to its adaptations to changing social and historical contexts, for example the Mesopotamian civilization 4500-500 BCE which focused largely on property, and used a record keeping system to account for property ownership and transactions on clay tablets using cuneiform script (SchmandtBesserat 1981, pp321-340), and stewardship concepts of manorial Europe, to the advancing from cash based systems to double entry accounting (Mathews and Perera 1996), accounting has also demonstrated its ability to embrace the values of those who practice it (Funnell 1998). Contemporary examples of the protean nature of accounting are the harmonization project of 
Australian Accounting Standards with International Financial Reporting Standards (CPA Australia 2007), and the existence of the standard setting bodies' Urgent Issues Group to provide interpretations of standards arising from ambiguous or changed circumstances.

The second attribute of myth identified is its ability to promote meaning, order and stability. This allows myth to function politically. Day (1984, pp249-250) argues "myth is created and perpetuated primarily because it actually works in social stability and integration of a group". Day argues this idea was put forward by Emile Durkheim in 1912 and "myth basically fulfils the function of establishing, maintaining and expressing social solidarity - it embraces cherished values" (Day 1984, pp249-250). It is argued that myth is a device that helps to maintain the political status quo for the salvation of society and to ensure an effective social system (Day 1984, pp249-250). Similarly, Eliade (1963, p19) suggests myth provides an origin of things and, therefore, allows control and manipulation of things and events. Echoing this, Kolakowski $(1972$, p5) argues myth allows a belief in a purposeful order. It allows a belief that there is something significant and permanent above the impermanence of events. Indeed the whole of our society revolves around the measuring and reporting of economic activity as a permanent yardstick to control and manipulate events, from governmental budgets to income measurement and taxation, to social security functions and investment in defence of national borders, and provision of economic justice via non-government organizations, and social action groups lobbying for measures against global warming. Accounting is intrinsic to the very meaning, order and stability of society in the ways it defines what to measure, how items are measured and how they are communicated.

The very accounting calculus, assets minus liabilities equals owners' equity, sets about the privileging of capital by accounting and has implied and reinforces an ordering of society. The accounting equation is expressed in terms of equity as opposed to for example in terms of creditors or labour. It is argued that accounting is exposed as an ideology that fosters capitalism and is complicit in wider social struggles (Tinker et al. 1982, p173). Gambling (1985) suggests this is akin to the idea of kingship or aristocracy, where debtor and creditor relationships described by the accounting calculus facilitate a social hierarchy. In this way accounting provides a means of structuring and is a way of handling social uncertainty. Accounting orders economic transactions, and records them in a meaningful way by classifying them, and gives stability to the economic events of an organization (Pondy 1983, p157). This aids political stability in that it supports current social structures (Dillard 1991). It also embraces a moral structure in that it embeds a privileging of capital over other interests such as labour or credit in accounting measurement (Francis 1990).

The third attribute of myth is that it must be believed with profound intensity. Belief is intrinsic to the power of myth. Myth cannot be reached by persuading, it is not a creature of science and reason. Belief is the "awakening of mythical consciousness" (Kolakowski 1972, p5). Myth works because it is believed with profound intensity, and the majority of people believe it to be valid. However, there is tolerance along a continuum in belief of myth. Day $(1984, \mathrm{p} 10)$ suggests that belief can range from "absolute belief in its truth" to "willing suspension of disbelief" as is the case with readers of fiction. For an effective myth, a reasonable number of people must have some belief; that is there must be some form of general acceptance. It is argued that mythical belief can range from deshi which is a belief by a specific community, binding it 
together with specific tenets, to marga ${ }^{3}$, which is mythical belief applicable to all of mankind (Day 1984, p10). Once myth is believed in the same way as history it is believed to be absolutely true because it is now given the status of being concerned with realities (Eliade 1963, pp18-19). From an accounting perspective Preston and Wright (1996, p115) argue that it is the belief in the power and knowledge contained in annual reports that create a meaningful reality. Such a custom as the presentation of an annual report is not seen as requiring justification (Gambling 1985). Their necessity and importance is implicit and reified through belief. This belief is institutionalised as a marga belief in society through legislation. Chambers (1989 p9) also referred to the unquestioned belief users of accounting give to its artefacts.

The fourth attribute of myth is that scientifically it cannot be shown to be rational. Day $(1984$, p2) suggests that myth is non-rational, or supra-rational. That is, it is beyond reason. This gives myth the power to perform functions that reason cannot, for example to tolerate ambiguity. Myth theory as a challenge to scientific method in accounting directly challenges much accounting based research that has as its underlying assumption rationality, such as agency theory, transaction cost theories or economic rationality or bounded rationality, and competitive game theory. In these applications accounting is seen as a tool, and not as something that reinforces and maintains and creates social relations and beliefs (Oakes and Hammond 1995, p57). Accounting is a social construct, and does not conform to physical laws. Its symbols, rules and constructs are self-referential. Understanding accounting as a myth-making device allows us to understand accounting as the creation of a symbolic reality in contrast to an objective reality, which transcends constraining logic and empirical falsifiability. In myth, the ordinary rules of logic are suspended and contradiction can be resolved within the myth. The accounting calculus provides its own internal system of logic. For example, dollars of different time values are happily added (for example an agreed exchange price repaid over time), subjective estimates embedded in depreciation and valuation methods are tolerated, arbitrary labels are applied such as only some pollution created is directly measured as an expense for the entity (Hines 1988, p254), for example carbon credits may be measured. This irrationality and tolerance allows the social system (accounting) to merely get on with it (Pondy 1983, p163), outside the bounds of scientific rationality.

Myth knowledge cannot be reconciled with phenomenological facts. Day (1984, pp10-11) gives the example of the flying carpet of the Arabian Nights. You cannot prove or disprove the carpet's existence, or its ability to fly. This knowledge is accepted with belief. In the narratives the rules of engagement allow for a flying carpet. In this way the myth is self referential. To use the example of profit, profit is "real" within the rules of engagement of the accounting calculus. However, profit may have an intersubjective meaning, for the example a high profit to a shareholder is perceived as desirable, but to the employee whose job was outsourced to cheap overseas labour, the profit conveys a different undesirable meaning. The profit is symbolic but ambiguous because the subject becomes a participant in its meaning. In this way it is not "objective" and transcends a constraining logic.

\footnotetext{
${ }^{3}$ Marga in this sense refers to the practice, procedures and understanding of accounting that is accepted universally and is ascribed to providing knowledge.
} 
The fifth attribute of myths is that they are held to be sacred. Ceremonies and rituals are two phenomena that operate in partnership with myth. Eliade (1963, pp16-17) suggests that it is not enough to know the origin of the myth, but that origin must also be recited. In recitation or performance of ritual, the myth is reified. Similarly Day (1984, p254) argues in a secular myth, ceremony is invoked, establishing a pattern of actions that are solemnly and repetitiously performed to mark a special occasion. Rituals and ceremonies have specific sociological intentions: they channel the emotions of an individual into a resolution; they minimize feelings of chaos and uncertainty by offering reassurance of a divine concern; they communicate and instruct; they create group unity and subordinate conflicts within a group for social bonding; they create a controlled environment that is above a mundane world; and they strengthen individual morale and confidence by encouraging imitation of a desired action (Day 1984, pp254-256). As it is identified that secular myth invokes ceremony, and that the presence of myth requires that it is recited and reified in ritualistic performance, the allegiances between myth and the ritualistic nature of accounting are evident. There is a low intensity secular ceremony of ritual in the everyday keeping of accounts. Gambling suggests that accounts are a record of the rituals they describe and part of a ritual themselves (Gambling 1985, p13). The accounts themselves may be regarded as representations of ancestors (Gambling 1985). Gambling (1987, p319) argues that much of accounting practice is ritualistic, with accounts being formal representations of dealings between various groups. A high intensity treatment of ritual occurs at discreet intervals in terms of the production of periodic financial statements and reports, which legitimize their author. The knowledge and truth of the technology of accounting in these financial reports is not doubted or questioned, and enjoys an everyday acceptance.

The sixth attribute of myth is that it takes the narrative form. Czarniawska-Joerges (1995, pp11-12) argues that narrative knowledge as opposed to scientific knowledge, should be part of the research tradition in organizational studies, suggesting that scientific knowledge can only be gained through, and is legitimized by narrative knowledge. This gives the application of the narrative form relevance in accounting research. Accounting collects organizational stories. Scientific reductionism may not capture all the underlying phenomena of the ritual of accounting and thus it is unable to give an unprejudiced and complete observation. A narrative depends upon time and sequence and thus implies a chronology suggesting causality (CzarniawskaJoerges 1995, p12). Narrative has two key characteristics, first it permits ambiguity and secondly enjoys paradoxes, where often explanation and interpretation are confused (Czarniawska-Joerges $1995, \mathrm{p} 15)$. The ability of narrative understandings to permit ambiguity and paradox supports the non-rational and supra-rational knowledge of myth understandings. This allows multiple stories to be told, and multiple stories to be valid in organizational studies of accounting. Pondy also identifies accounting as a narrative form, suggesting its allegiance with myth. He suggests that accounting practice is metaphorical (Pondy 1983, p159). Accounting is mythical because it is a group of metaphors for economic events that take place in a different time and space. (This relevance of time and space will be discussed further in the next section). Pondy challenges that any social organization (naturally occurring) and any formal organization (rational model of conscious design) are "distinct phenomena subject to different laws"; that is, the social which is not naturally occurring versus the form design of the conscious designer. When these are treated as the same family of kinship or belief systems we can see myths and metaphors in a new light (Pondy 1983, p158). The metaphors of accounting not only allow social change, but facilitate it (Pondy 1983, Young 2003). Metaphors may carry several meanings at once, both literal and nonliteral (Pondy 1983, p165). 
The seventh attribute of myth is that myth suspends time and space. Eliade (1963, pp18-19) argues that myth space is perpetual because it is recollected and re-enacted. Such reiteration of the myth allows the myth to exist or step outside chronological time. Kolakowski (1972, p4) describes this stepping outside chronological time as an attempt to stop time by creating a mythical form of time that allows us to see change and accumulations. Myth is never of the present. It describes the past for the future. This reification and distortion of chronological time allows what is physically transient to become permanent in myth (Kolakowski 1972, p5). An appreciation of this mythical attribute of accounting is documented. Chambers argued that accounting does not exist in a continuum of time. Rather, accounting events (transactions) occur at specific points in time. Anything before this point is the past, anything ahead is the future (Chambers 1989, p7). Accounting events occur at these moments in chronological time, and they only make sense in the context of what went before them. Chambers (1989, pp14-15) accused accounting of making use of "higgledy-piggledy" time, giving the examples of balance sheets which are at a certain date but which contain assets expressed as prices at earlier dates, or the representation of a depreciation expense making use of a past-dated price of the asset (historical cost) and a future selling prices of the asset (scrap value) to impose an assumed pattern of devaluation. This is represented to be of the present, but it is derived from historical events of the past and anticipated outcomes of the future. Neither come from the present moment. Chambers $(1989$, p14) also accuses accounting practice of time inversion, an argument that also supports the proposition that accounting uses myth time outside chronological time. Time inversion occurs when present value calculations are used to bring estimated values of future options into the present to allow comparison.

The analysis of income figures in accrual accounting by Takatera and Sawabe (2000) also illustrated this point. Takatera and Sawabe argue that "money links different points of time in two ways: physically and notionally" (2000, p789). Time is linked physically because money represents purchasing power in the future. Time is linked notionally because you can deal with future events in the present, for example commodities of the future can immediately be bought and sold in the present through futures markets. It is argued that accounting provides a framework or taken for granted set of rules that relates time and space and provides the intersubjective ground (a social space) for transactions across time. Accounting creates artificial dimensions of space and time; "specific procedures instituted in the accounting system generate artificial spaces where time flows differently from the outside world" (Takatera et al. 2000, p789). It is argued that under the entity concept of accounting, artificial organizational time is created distinct from the chronological sense of time of the market in which it is situated.

Like all good myths, accrual accounting suspends chronological time. It does this by making an assumption that money measurements are useful despite them not holding a constant value across time. In measuring transactions in historical cost accrual accounting, any change in purchasing power is assumed to be irrelevant. This of course is a fiction, but a willing suspension of disbelief is sustained. For accounting to artificially partition time into accounting periods, several assumptions concerning time and money were necessary. Takatera et al. (2000, p792) suggest that time differences in transactions are recognized through the time value of money. Historical cost accounting suspends this sense of time in transactions by assuming there is no change in the value of the money used to record the transactions. This is equivalent to assuming that no time passes between the transactions. "The accrual accounting system is capable of 
creating internal space independent of external time flows" (Takatera et al. 2000, p792). Suspended chronological time is a means of supporting the reification of the social institution of accounting. This is done by imposing an internal logic that is widely accepted (Takatera et al. 2000, p790).

The eighth attribute of myth is that it contains symbolism. Day argues that myths need symbols, and a symbol "represents not an external reality but a psychic and spiritual reality" (Day 1984, p11). Symbols are ambivalent and generate rich and perplexing meanings. A symbol's meaning is constructed by the user of the symbol, and may mean subtly different things to different users. For example a nation, while being a symbol of national pride, may bring sadness or anger to some in the case of war. In this way symbols participate in what they point towards. Dowden (1992, p9) suggests that symbols are formed from the myths of a shared culture. Symbols are participants in the myth, allowing evocation, suggestion and transformation. As such, symbols are useless for empirical and logical truth-testing. Accounting makes extensive use of symbols and symbolism. There are significant implications for how we go about studying and understanding the practice of accounting. Profit symbolizes success, wealth and a contribution to society in the form of taxes incurred. However, while a profit is psychologically better, it may not represent an external reality, for example Enron recorded large profits before their collapse (Cullinan 2004). The profit itself worked at a symbolic level for the investors. Another example can be found in what being a creditor as opposed to a debtor symbolizes. Technically they are just two states of economic being, but are symbolically accorded different status by society. Another example is the symbol of accountability that the audit function evokes in accounting, again not representing accurately an external reality of financial certainty and resulting in the identified expectation gap of audits. Macintosh et al. (2000, pp14-15) argue that accounting signs and images today are simulacrum, where the boundary between accounting concepts and reality has melted or imploded, to form a new hyperreality in which signs and images and models operate and function detached from the reality that they originally represented. In this way accounting symbols become participants in the reality, and not just representations of it.

The ninth attribute of myth is that it is believed to provide valuable knowledge and guidance. Eliade suggests that myths are sacred, exemplary and significant and that "the foremost function of myth is to reveal the exemplary models for all human rites and all significant human activities" (1963 p1). Myths teach how to repeat creative acts and thus the story represents knowledge that is handed down and also represents power derived from the knowledge (Eliade 1963, p15). Similarly, Campbell and Moyers (1988), as cited by Parkin (1998, p11) suggest "myths offer life models but the models have to be appropriate to the time in which you are living". Day (1984, p16) suggests that myths hold valuable knowledge and guidance, and that they are more than a "cultural decoration or an aesthetic embellishment" because they hold "real knowledge and sublime truth". There is the implication that failure to follow the proper conduct as suggested by the myth can cause injury to oneself (Day 1989, p250). Similarly, Kolakowski (1972, p5) argues myths are acts of affirming values. They are meaninggiving interpretations of the world. Accounting and accountability is acknowledged by society to be essential to the commercial world. It holds its valuable knowledge in its construction of normative accounting standards and the development of a conceptual framework, and its exemplary and significant role is seen in its status as a profession and public recognition in the academic corpus. The accounting profession derives its power and legitimacy from the guidance 
obtained in using and developing the accounting standards. All stem from this body of knowledge and in this way they are more than symbolic, but are active in the practical application of accounting.

\section{MYTH THEMES}

Accounting can be demonstrated to operate in the three themes identified in myth theory, namely etiological, soteriological, eschatological themes. Etiological myths are creation stories that explain the origin and reason for things. Journals, ledgers, profit and loss statements and balance sheets all explain the origin of the current financial situation of an organization. The branch of critical accounting attempts to explain the current societal status quo through the socially constructing and socially constructed aspects of accounting in society over time (Hines 1988). These accounts explain financially whence the organization came, and in doing so are operating at the level of etiological myth, because they are constructing how a society thinks about itself.

Soteriological myths contain knowledge that has the ability to rescue the believer of the myth from imminent disaster. Prophetic myths are concerned with the future and are characterized by a great deal of symbolism. The rhetoric of accountability fulfills this role. Organizations must be accountable to their stakeholders, historically in the form of probity and with the introduction of managerialism, be accountable in form of efficiency and effectiveness (Funnel and Cooper 1998). Good accountability and sound financial management avoid financial disaster, financial waste and poor corporate governance. Such themes are communicated with little or no acknowledgement given to non-financial factors such as global warming or natural disaster, but are believed in the short term to be real for the functioning of society.

Eschatological myth is concerned with the future, but more specifically predicts impending disaster if the values and rules of the myth are not followed. If good accounting practice is not followed, and if accounting standards do not meet business' needs, then economic productivity will suffer. A contemporary example can be found in the reasons given for the harmonization of Australian Accounting standards with International Financial Reporting Standards. This was justified with the argument that if Australia continued to use their unique accounting standards, this would restrict the flow of foreign investment into Australia, as promoted by the Federal Government in the Corporate Law Economic Reform Program (Deegan 2005). Similarly the Australian Accounting Standards Board in their Policy Statement 4 (2002) emphasized the desirability for harmonization, stating "The globalization of economic activity has resulted in an increased demand for high quality, internationally comparable financial information".

\section{CONCLUSION}

The value of approaching accounting as a myth making device is that it uniquely demonstrates a new paradigm for understanding and analyzing accounting practice. By viewing accounting as a form of myth making in society, positive accounting discourses are obfuscated and their underlying economic rationalist assumptions and rhetoric is challenged. Such an approach demands further research of accounting organizational studies at the micro level to give visibility to accounting mythical structures at a contextual level. While such specific details are accepted as being unique to the situation of any study, it is proposed that such individual narratives can 
form themes relevant beyond their contexts, because meanings ascribed in each site are derived from prevailing institutional structures and form a fabric of socially accepted meanings.

In exploring accounting, not with the predisposition to a sophisticated technology, but rather with a primitive view of accounting as myth making, it can be viewed openly as a social device, and we give accounting researchers a tool to make understandings of accounting that are the realm of the social aspect in an organization more visible. We illuminate experiences and understandings of the actors affected by accounting practice that go beyond the technical. We can explain how accounting is used in constructing their world picture. Through viewing how accounting is engaged with, interpreted, modified and avoided by actors in a social setting through the lens of myth theory, and by considering how accounting interacts with the cultural values of the social setting, we gain a deeper understanding of how actors implicitly use accounting to make sense of their daily lives. Exposing partial understandings of accounting enables us to be socially aware in our engagement with the discipline.

\section{REFERENCES}

(1989) Australian Oxford Dictionary, Edited by George and Beryl Turner, Oxford University Press, Melbourne.

Agger, B. (1991) "Critical Theory, Poststructuralism, Postmodernism: Their Sociological Relevance”, Annual Review of Sociology, Vol. 17, pp.105-131.

Arrington, C. E. and Francis, J. (1989) "Letting the Chat Out of the Bag: Deconstruction, Privilege and Accounting Research", Accounting, Organizations and Society, Vol. 14, pp.1-29.

Australian Accounting Standards Board (2002) Policy Statement 4 International Convergence and Harmonisation Policy", April.

Barthes, R. (1957) Mythologies, Seuil, Paris.

Burchell S., C. Clubb, A. Hopwood, J. Hughes and J. Nahapiet (1980) "The roles of accounting in organizations and society", Accounting, Organizations and Society, Vol. 5, No. 1, pp.5-30.

Burn, A. (1970) "Introduction" in Herodotus The Histories, Penguin Books, The Chaucer Press Ltd, Suffolk.

Chambers, R. (1989) "Time in accounting”, Abacus, Vol. 25, No.1, pp.7-21.

Chua, W.F. (1986)[a] "Radical Developments in Accounting Thought", The Accounting Review, Vol. LXI, No. 4, pp.601-632.

Chua, W. F. (1986)[b] "Theoretical Constructions of and by the Real", Accounting, Organizations and Society, Vol. 20, No.2, pp.111-145.

Chwastiak, M. (1999) "Deconstructing the Principal-Agent Model: A View from the Bottom", Critical Perspectives on Accounting, Vol. 10, No. 4. pp.425-441.

Cooper, D. and T. Hopper (1987) "Critical Studies in Accounting", Accounting, Organizations and Society, Vol. 12, No4/5., pp.407-414.

CPA Australia (2007) Accounting Handbook, M. Shying and J. Ngiam Editors, Pearson Education Australia.

Cullinan, C. (2004) "Enron as a symptom of audit process breakdown: can the Sarbanes Oxley Act cure the disease?" Critical perspectives on Accounting, Vol. 15, pp.853-864.

Czarniawska-Joerges, B. (1995) "Narration or Science? Collapsing the Division in Organization Studies", Organization Vol. 2(1), pp.11-33. Sage London, Thousand Oaks and New Delhi.

Day, M. (1984) The many meanings of myth, Lanham, MD, University Press of America.

Deegan, C. (2005) Australian Financial Accounting, $4^{\text {th }}$ Edition, McGraw Hill Irwin, North Ryde.

Dillard, J. (1991) “Acccounting as a Critical Social Science”, Accounting, Auditing and Accountability Journal, Vol. 4 No. 1, pp.8-28.

Dowden, K. (1992) The Uses of Greek Mythology, Routledge, London.

Dunn, C. and McCarthy, W. (1997) "The REA Accounting Model: Intellectual Heritage and Prospects for Progress" Journal of Information Systems Spring, pp.31-51.

Eliade, M. (1963) Myth and Reality, translated by W. Trask, Harper and Row, New York.

Francis, J. (1990) "After Virtue? Accounting as a Moral and Discursive Practice", Accounting, Auditing and Accountability Journal, Vol. 3, No. 3, pp5-17.

Frye, N. (1982) The Great Code: The bible and literature, Routledge and Kegan Paul, London. 
Funnell, W. (1998) “Accounting in the service of the holocaust" Critical Perspectives on Accounting”, Vol. 9, No. 4, pp.435-464.

Funnell, W. and K. Cooper (1998) Public Sector Accounting and Accountability in Australia, UNSW Press, Hong Kong.

Gaffikin, M. (1988) "Legacy of the Golden Age: Recent Developments in the Methodology of Accounting", ABACUS, Vol. 24, No. 1, pp.16-36.

Gambling, T. (1985) “Accounting for Rituals”, Accounting Organizations and Society, Vol. 12, No. 4, pp.319-329.

Hines, R. (1988) "Financial Accounting: In Communicating Reality, We Construct Reality", Accounting, Organizations and Society, Vol. 13, No. 3, pp.251-261.

Hopwood, A. (1978) "Towards an Organizational Perspective for the Study of Accounting and Information Systems", Accounting, Organizations and Society, Vol. 3, No. 1, pp.3-13.

Kedslie, M. (1990) "Mutual self interest - a unifying force; the dominance of societal closure over social background in the early professional accounting bodies", The Accounting Historians Journal, Vol. 17, No. 2, December.

Kolakowski, L. (1972) The Presence of Myth, University of Chicago Press, Chicago.

Laughlin, R. (1987) "Accounting systems in organizational contexts: a case for critical theory", Accounting, Organizations and Society, VOl. 12, No. 5, pp.479-502.

Lehman, C. and Tinker, T. (1987) "The 'Real' Cultural Significants of Accounts", Accounting Organizations and Society, Vol. 12, No. 3, pp.68-95.

Levi-Strauss, (1978) Myth and Meaning, Routledge and Kegan Paul, London.

Lyotard, J. (1984) The postmodern condition : a report on knowledge translated

from the French by G. Bennington and B. Massumi, Manchester, Manchester University Press.

Macintosh, N., T. Shearer, D. Thornton and M. Welder (2000) “Accounting as simulacrum and hyperreality: perspectives on income and capital", Accounting, Organizations and Society, Vol. 25, pp.13-50.

Mathews, M. R. and Perera, M. H. B. (1996) Accounting Theory and Development, $3^{\text {rd }}$ edition, South Melbourne, Nelson.

Morgan, G. (1988) “Accounting as reality construction: towards a new epistemology for accounting practice”, Accounting, Organizations and Society, Vol. 13, No. 5, pp.477-485

Oakes, L. and T. Hammond (1995) "Biting the epistemological hand: feminist perspectives on science and their implications for accounting research", Critical Perspectives on Accounting, Vol. 6, pp.49-75.

Parkin, M. (1998) Tales for Trainers: Using Stories and Metaphors to Facilitate Learning, Kogan Page Ltd, London.

Pondy, L. (1983) "The role of metaphors and myths in organizations and in the facilitation of change", in L. R. Pondy, P.J. Frost, G. Morgan and T.C. Dandridge (Editors), Organization Symbolism, Greenwich, JAI Press, pp.157-166.

Preston, A. and C. Wright (1996) "Imag[in]ing Annual Reports", Accounting, Organizations and Society, Vol. 21, No. 1, pp.113-137.

Schmandt-Besserat, D. (1981) "From Tokens to Tablets: A Re-evaluation of the So-Called 'Numerical Tablets" Visible Language, Vol. 15, No. 4, pp.321-344.

Sterling, R. (1990) "Positive Accounting: An Assessment", ABACUS, Vol. 26, No. 2, pp.97-135.

Takatera, S. and N. Sawabe (2000) "Time and space in income accounting", Accounting, Organizations and Society, Vol. 25, pp.787-798.

Tinker,T, B. Merino, M. Neimark (1982) "The normative origins of positive theories: ideology and accounting thought", Accounting, Organizations and Society, Vol. 7, No. 2, pp.167-200.

Watts, R. (1995) "Nature and Origins of Positive Research in Accounting", Accounting theory a contemporary review, S. Jones, C. Romano and J. Ratnatunga editors, Harcourt Brace Marickville NSW, pp.297353.

Young, J. (2003) "Constructing, persuading and silencing: the rhetoric of accounting standards" Accounting, Organizations and Society, Vol. 28, pp621-638. 